\title{
A aula-oficina na caminhada de aprender a ser professor de História
}

\author{
History classroom as a workshop in demand of learning to be a History \\ teacher
}

\section{La clase de historia como un taller, una forma de aprender a ser profesor de Historia}

\author{
Marília Gago' \\ Universidade do Minho, Professora. \\ https://orcid.org/0000-0002-3109-8915
}

Resumo: Ser professor de História implica o engajamento de várias áreas do saber e exige a operacionalização de operações complexas adequadas ao contexto educativo em que se inscreve. A formação de professores tem de ser capaz de desafiar e preparar os futuros professores de História para lidarem em progressão com essas operações. A aula-oficina é um caminho proposto pela educação histórica que parece se adequar ao desenvolvimento de literacia e consciência histórica. 0s dados de investigação em Educação Histórica têm demonstrado que quando os aprendentes são desafiados a resolver tarefas com base em fontes, analisadas com questões de graus distintos de complexidade, promove-se o desenvolvimento do pensamento e o conhecimento histórico. Assim, propõe-se a partilha de dados de um estudo qualitativo em linha com a Grounded Theory (Teoria fundamentada), realizado por meio de uma amostragem de conveniência entre 20 alunos do mestrado em ensino da História do terceiro ciclo do ensino básico e do ensino secundário de uma universidade do Norte de Portugal, em várias fases de formação e de recolha de dados, numa lógica longitudinal e em linha com os princípios da aula-oficina - das ideias prévias à metacognição. As ideias foram recolhidas por meio de questionário de resposta aberta acerca dos seguintes construtos: consciência histórica, identidade e profissionalismo docente. As ideias partilhadas pelos alunos, futuros professores de História, sugerem que as tarefas-desafios propostas acompanhadas pelo debate das soluções encontradas e da reflexão continuada acerca do processo promoveram a consciência do seu papel e propósito de professor

Pós-doutora em História da Educação pela Universidade do Minho; Doutora em Educação, área de metodologia do ensino de História e Ciências Sociais, pela Universidade do Minho. 
de História numa lógica de crescente complexidade em termos de identidade pessoal-histórica e de profissional-docente.

Palavras-chave: Educação histórica. Formação de professores. Profissionalismo docente. Aulaoficina.

Abstract: Being a history teacher implies the engagement of various areas of knowledge and requires the operationalization of complex operations appropriate to the educational context in which it is inserted. Teacher education must be able to challenge and prepare future history teachers to deal progressively with these operations. History class as a workshop is a path proposed by History Education that seems to suit the development of literacy and historical consciousness. History Education research data have shown that when learners are challenged to solve tasks with varying degrees of complexity their History thinking, and knowledge is developed. Thus, it is proposed to share data from a qualitative study in line with Grounded Theory, conducted through a convenience sampling, among twenty students of the Master's degree in the teaching of History of one university on the north of Portugal, in various stages of training and data collection, in a longitudinal logic. The ideas were collected through an open-ended questionnaire about the following constructs: historical awareness, identity and teaching professionalism. The ideas shared by the students, future history teachers, suggest that the proposed challenge tasks accompanied by the debate of the solutions found and the continuous reflection about the process promoted the awareness of their role and purpose as a history teacher in a logic of increasing complexity in terms of personal-historical and professional identity.

Keywords: History education. Teacher education. Teacher professionalism. Workshop history classroom.

Resumen: Ser profesor de historia implica la participación de diversas áreas del conocimiento y requiere la concretización de operaciones complejas apropiadas al contexto educativo en el que se inserta. La formación del profesorado debe ser capaz de desafiar y preparar a los futuros profesores de historia para afrontar progresivamente estas operaciones. La clase de Historia como un taller es un camino propuesto por la Educación Histórica que parece adaptarse al desarrollo de la conciencia histórica. Los datos de la investigación en Educación Histórica han demostrado que cuando se enfrentan los aprendientes con desafíos para resolver tareas con diversos grados de complejidad promueven el desarrollo de su pensamiento y conocimiento histórico. Por lo tanto, se propone compartir datos de un estudio cualitativo en línea con la teoría fundamentada (Grounded Theory), realizado a través de una muestra de conveniencia, entre veinte estudiantes del Máster en la enseñanza de la historia del tercer ciclo de educación primaria y secundaria de una universidad del norte de Portugal, en varias etapas de formación, en una lógica longitudinal y en línea con los principios de la clase como un taller - desde ideas previas a la metacognición. Las ideas se recopilaron a través de un cuestionario abierto sobre los siguientes constructos: conciencia histórica, identidad y profesionalismo docente. Las ideas compartidas por los estudiantes, futuros 
profesores de historia, sugieren que las tareas de desafío propuestas acompañadas por el debate de las soluciones encontradas y la reflexión continua sobre el proceso promovieron la conciencia de su papel y propósito del profesor de historia en una lógica de complejidad creciente en términos de identidad personal-histórica y profesional.

Palabras clave: Educación histórica. Formación de profesores. Profesionalismo docente. Lasse de historia "como un taller".

Recebido em 15 de agosto de 2019

Aceito em 6 de fevereiro 2020

Publicado em 17 de junho de 2020

\section{APRENDER HISTÓRIA - A AULA-OFICINA}

Aprender e ensinar História, no quadro de investigação em educação histórica, envolve várias áreas do saber. É necessário saber em profundidade as histórias que queremos contar, saber como se faz História, saber como se aprende e saber como podemos contribuir/desafiar para essa aprendizagem. 0 processo de ensino-aprendizagem de História envolve a História, a Epistemologia da História, a Cognição Situada e, de forma mais ampla, as teorias cognitivistas em linha com o Construtivismo Social.

Considera-se que, em educação histórica, aprender significa "saber isto" e "saber como". Assim, quando se desenvolve o pensamento histórico, pretende-se que quem aprenda saiba história(s), desenvolva conhecimentos/conceitos substantivos, mas, em simultâneo, que desenvolva a sua forma de saber como se faz História, ou seja, que compreenda como se reconstrói a realidade dos seres humanos quer seja passada, presente ou horizonte(s) de expectativa(s). Dessa forma, com base em realidade(s) dos seres humanos que reconstruímos, atendendo aos seus pensamentos, aos seus desejos, aos seus sonhos, aos seus receios, às suas ações e às consequências que anteviram na altura, compreende-se o mundo ao qual pertencemos. Considera-se então, que, com base na realidade substantiva que lemos/interpretamos por meio das questões que colocamos, reconstruímos a realidade de forma narrativa, que é a face material da História. Temos de dominar o conteúdo substantivo da História, o que aconteceu, mas quando falamos de História temos de ser capazes de fazer sentido, ou seja, temos de compreender como se sabe historicamente, como se faz História. Assim, colocamos questões faciais à realidade em estudo lo quê, quando, onde, como...), mas para a compreensão da realidade histórica temos de colocar questões em linha com as operações metodológicas da própria ciência histórica (metahistória). Nesse sentido, é fundamental que se questione, por exemplo, por que é que tal aconteceu... em que 
perspetiva... em que escala temporal...? Quais as intenções do autor? 0 que podemos saber sem que tenha intenção? 0 que podemos/devemos procurar para validar essa informação? É por que muitos dizem que devemos acreditar ou uma pessoa pode ser a única a ter perspetiva mais equilibrada?

Partilha-se a ideia de que aprender História permite que se veja o Mundo de forma(s) mais complexa(s). Considera-se que ser historicamente competente/educado significa ter uma reorientação cognitiva acerca da(s) forma(s) como se vê o mundo e que a literacia histórica é transformativa no modo como compreendemos a realidade (LEE, 2011). Os educadores/ professores de História questionam-se como podem desenvolver essas ferramentas de compreender o mundo nos alunos. A História é genuinamente diversa, multiperspectivada e pode desenvolver em todos modos mais sofisticados de pensar, que possam contribuir para a compreensão de "mundos estrangeiros" (como o passado) e desenhar cenários possíveis com base na crítica de vestígios, na inferência, na leitura e criação de uma narrativa histórica explicativa das realidades que pretendemos reconstruir ancorada em evidência. A História pode abrir, desenvolver o nosso modo de compreender o eu, o nós, o outro, isto é, compreender a(s) realidade(s) e tomar decisões.

As ideias partilhadas encontram-se em sintonia com os três princípios propostos pela cognição situada em linha com as teorias cognitivistas e o construtivismo social (DONOVAN; BRANSFORD, 2005). Para que a aprendizagem seja significativa, considera-se que é necessário atender a:
a. ideias prévias: conhecer, analisar e construir as tarefas-desafios com base nessas ideias;

b. construção de tarefas-problemas a serem desenvolvidas pelos alunos (de qualquer grau de ensino) atendendo ao conhecimento substantivo ("saber isto") e aos conceitos meta-históricos ("saber como");

c. fomentar a metacognição: momentos de reflexão acerca de como o pensamento se desenvolveu.

Germinari (2011) considera que esses três núcleos são, também, os enfoques das pesquisas em Educação Histórica, quer no Brasil quer noutros locais do mundo (como, por exemplo, Portugal e Reino Unido). Esses princípios e enfoques são operacionalizados no que Barca (2004) propôs como aula-oficina. Ou seja, torna-se necessário conhecer o modo como os alunos (sejam alunos do ensino básico, secundário ou futuros professores) compreendem o mundo que os rodeia. Essas ideias fazem parte das suas vivências e experiências 
pessoais, e se não as conhecermos não teremos qualquer tipo de oportunidade de as desafiar conscientemente, ou seja, não teremos a oportunidade de as alterar. Partilhandose esse paradigma educativo, pretendemos que os nossos alunos sejam intervenientes, "os professores não podem ser formados (passivamente). Eles formamse (ativamente)." (DAY, 2001, p. 17). Ou seja, o professor e/ou o formador de professores deve conhecer o quadro mental dos seus alunos, o que implica

\footnotetext{
[...] ouvir mais a voz dos professores le futuros professores], associálos mais à investigação, ter mais em consideração as culturas docentes, não para as eternizar, mas para que elas mudem de dentro para fora e, não como se tem pretendido e apesar de todos os discursos em contrário de fora para dentro. (ESTRELA; ESTRELA, 2006, p. 79).
}

Os futuros professores, ao longo do seu percurso escolar, foram criando um conjunto de ideias e imagens acerca do que é ensinar/aprender. Ou seja, os futuros professores, quando iniciam o seu percurso específico de formação para o ensino, são já frutos de um caminho de, pelo menos, 15 anos de ensino, ou seja, experienciaram o seu contexto profissional, embora noutro papel, durante muito tempo. Observaram os seus professores, desenvolveram atividades e tarefas, conhecem o habitat da sala de aula e da escola. Esse contato próximo e duradouro com a realidade de "ser professor" leva ao que Lortie (1975) define como "aprendizagem por observação", que é acomodada ao quadro pessoal, às suas ideias acerca de ensino, de aprendizagem, bem como acerca do que significa ser professor. De acordo com o mesmo autor, essa cultura latente é recordada, re-significada durante a formação inicial de professores, e se não for tornada consciente e desafiada, manter-se-á na prática profissional. Assim, a proposta na formação de alunos, futuros professores, é conhecer as ideias prévias destes e com base nestas desenhar tarefas desafiadoras que os façam refletir acerca de outras possibilidades e perspetivas, e com base nessa reflexão decidir, planejar e agir. Parece ser urgente "combater" a ideia de que os professores ensinam como viram ensinar, e para tal, temos de "criar espaços no contexto da formação inicial para explicitar essas crenças e essas teorias implícitas que os alunos trazem para a sua formação inicial, no sentido de potenciar uma reflexão e questionamento de fundamentos sobre o processo de tornar-se professor." (FLORES, 2010, p. 3).

Por outro lado, os futuros professores procuram que thes seja dito, que thes seja entregue uma receita de como devem ensinar. Mas a apresentação da(s) teoria(s) não é suficiente, é necessário que a formação/educação de professores combine/articule experiências que o formador de professores deseja desenvolver com a promoção de reflexão acerca desses mesmos desafios/tarefas/experiências. Em vez de se estar focalizado na 
questão "qual é a melhor teoria para ser apresentada" (KORTHAGEN, 2010, p. 104, tradução nossa), que está em linha com a fragmentação, será mais útil focalizar na questão:

\begin{abstract}
que tipo de experiências podem ser organizadas para que, simultaneamente, possam efetivamente contribuir para a prática do futuro professor e que possam servir como "rampa de lançamento" para a reflexão conjunta com a comunidade profissional de forma a promover o desenvolvimento adequado? (KORTHAGEN, 2010, p. 104, tradução nossa).
\end{abstract}

Assim, considera-se que a formação/educação de professores siga uma abordagem designada por Korthagen et al. (2001) como realista. Ou seja, a organização de experiências realistas e definidas adequadamente às necessidades e preocupações dos futuros professores, e que simultaneamente os prepare para um processo de desenvolvimento mais sofisticado do seu pensamento como professor de História. Mais uma vez, para além de "saberem isto" acerca de como ensinar, "saberem como" se constrói o saber acerca de como se aprende/ensina História. Aqui chegados, o caminho aponta-nos para a necessidade de conhecermos como aprendemos, como sabemos, como compreendemos, ou seja, para a metacognição. A metacognição é uma operação cognitiva que visa refletirmos acerca do modo como conhecemos, compreendemos a(s) nossa(s) realidade(s) e como tomamos decisões. Esse processo de monitorização e regulação do processo de ensino-aprendizagem, nosso ou de outros, deve ir desafiando, ajustando, orientando, não ao que alguém definiu "no vazio" como necessário para si, mas com base na sua/nossa realidade em articulação com a investigação em educação histórica (DAY, 2001).

As propostas da investigação em educação histórica operacionalizadas em experiências de aprendizagem que têm em conta o mundo prévio de ideias e necessidades dos alunos/futuros professores de História, focalizadas em tarefas-desafios em que se "sabe isto" mas também se "sabe como", bem como no desenvolvimento de competências de reflexão acerca da sua compreensão e da sua identidade, parecem ser uma resposta adequada e articulada com a(s) epistemologia(s) da educação histórica. Nesse quadro temos de pensar na aprendizagem e no ensino fazendo uso de diferentes "lentes" dadas por várias áreas de saber (URBAN, 2015).

\title{
2 APRENDER A SER PROFESSOR DE HISTÓRIA - UM CAMINHO A PERCORRER
}

Mas o que é ser professor? Partilha-se a definição de Sachs (2005), que considera que a identidade profissional do professor é nuclear para a profissão de ensino. Esta 
providencia um campo conceptual e de ferramentas para os professores construírem as suas próprias ideias acerca de "como ser", "como agir" e "como compreender" o seu trabalho e o seu papel na sociedade. A identidade do professor não é algo fixo nem imposto, antes é algo negociado por meio da experiência do(s) sentido(s) feito(s) da(s) experiência(s). Essa concepção de identidade profissional do professor está em linha com a identidade pessoal, a qual, enfatiza-se, não pode ser ensinada ou adquirida, mas é algo que se altera com a experiência, é o eu a ir sendo (RÜSEN, 1993).

Globalmente assistimos a recentes reformas que pretendem a descentralização e a "mercantilização" da educação, provocando o surgimento de um conjunto de paradoxos acerca da natureza do ensino como profissão, da identidade profissional e do desenvolvimento profissional dos professores (ver os estudos de Rede Latino-Americana dos Estudos Sobre Trabalho Docente (Redestrado) e Teachers Exercising Leadership (TEL), Portugal).

Day e Sachs (2004) e Sachs (2001) apontam três paradoxos acerca do profissionalismo docente no contexto das últimas reformas educativas em vários pontos do mundo. Assim, parece existir:

a. a necessidade (e a defesa) de um maior profissionalismo docente reinventando a identidade profissional dos professores e, ao mesmo tempo, assiste-se à "desprofissionalização" dos professores lesvaziamento de competências específicas), à intensificação do seu trabalho burocrático de prestação de contas mediante a imposição do currículo definido externamente e de sistemas de monitorização, de avaliação e de supervisão;

b. o reconhecimento da necessidade de repensar a prática da sala de aula, pois é uma tarefa extremamente exigente e que é crucial para as demandas futuras, mas são alocados cada vez menos recursos para apoiar a aprendizagem/ formação dos professores;

c. a exortação do ensino como atividade autonôma, mas simultaneamente é alvo de regimes estandardizados com definição de metas e a criação de rankings baseados em padrões.

$\mathrm{Na}$ atualidade, parecem existir dois tipos de profissionalismo em debate: 0 profissionalismo gerencialista e o profissionalismo democrático. Para Day e Sachs (2004), o profissionalismo gerencialista caracteriza-se por ser baseado e orientado para os resultados, regulado externamente com o objetivo de implementar políticas, que têm como foco a competitividade baseada no mercado, no controle e na aceitação/cumprimento de normas. Já 
o profissionalismo democrático focaliza-se no desenvolvimento da profissão caracterizando-se pelo ativismo e não apenas pelo cumprimento de reformas e normas impostas externamente, ou seja, combate o controle e a submissão. Assim, os sistemas de eficiência e prestação de contas e as crescentes formas de gerencialismo enfatizam uma visão de professor enquanto técnico ou executor, que deve ser gerido em vez de ser considerado um profissional que toma decisões e usa o juízo discricionário no seu trabalho (FLORES, 2011). Nesse sentido é necessário dar voz aos futuros professores e aos professores, conhecer o seu mundo prévio, o seu contexto, as suas necessidades e agir educativamente de forma desafiadora, promovendo o seu crescimento transformativo (não apenas crescimento aditivo de mais informações, técnicas, estratégias, entre outras) e o seu desenvolvimento profissional em linha com um profissionalismo democrático. Assim, Sachs (2001) considera que se podem identificar cinco valores centrais que constituem os fundamentos de uma abordagem pró-ativa e responsável do profissionalismo:

1. aprendizagem: em que os professores e futuros professores são encarados como aprendentes, individualmente, com os seus colegas e alunos;

2. participação: em que os professores e futuros professores pensam em si próprios como agentes ativos nos seus próprios mundos profissionais e educativos;

3. colaboração: em que a participação é exercida dentro e entre comunidades internas e externas;

4. cooperação: por meio da qual os professores e futuros professores desenvolvem uma linguagem comum e a tecnologia para documentar e debater as suas práticas, bem como os seus resultados;

5. ativismo: em que os professores e futuros professores se envolvem publicamente em questões relacionadas, direta ou indiretamente, com a educação e com a escolaridade, enquanto parte integrante dos seus propósitos morais da sociedade.

A investigação em educação histórica, que pretende contribuir para o desenvolvimento do pensamento histórico quer de alunos quer de professores, alicerça-se em estudos de investigação que partem do contexto social real e, com base neste, desenham experiências educativas desafiadoras atendendo seja aos conteúdos/conceitos substantivos seja metahistóricos. Ou seja, para além de se "saber isto" de História, isto é, a história substantiva acerca de uma realidade/assunto do passado, é necessário saber "como é que se faz História", em linha com a metodologia da própria ciência histórica e o trabalho do historiador. Nessa linha, considerou-se premente desenhar a formação inicial de professores portugueses de 
História de $3^{\circ}$ ciclo e secundário ancorada nos princípios cognitivistas e construtivistas sociais operacionalizados em experiências de aprendizagem em linha com a aula-oficina.

\section{ESTUDO}

Em Portugal, para se tornar professor de História, atualmente, é exigido que durante a licenciatura, que conta com três anos letivos de formação, o aluno tenha tido sucesso a um número de unidades curriculares do âmbito da História que espelhem um determinado esforço e trabalho definido atendendo ao sistema europeu de transferência de créditos, ou seja, o aluno terá que ter १२० European Credit Transfer System (ECTS) (esses créditos espelham o esforço que o aluno teve ao concretizar com aproveitamento as unidades curriculares/disciplinas que frequentou num curso do ensino superior europeu). Após essa primeira fase, os alunos do ensino superior podem concorrer e ingressar num mestrado de ensino de História no $3^{\circ}$ ciclo e no ensino secundário para poderem ser profissionalizados. A profissionalização em ensino é determinante para se tornar professor em Portugal e aceder nas melhores condições ao concurso nacional de colocação de professores nas escolas públicas portuguesas. Esse mestrado decorre ao longo de dois anos letivos. 0 primeiro ano é desenvolvido, essencialmente, na universidade, e num segundo ano, para além de prática pedagógica supervisionada implementada nas escolas, os alunos têm acompanhamento/ supervisão da sua prática pedagógica e unidades curriculares na universidade.

No âmbito deste mestrado, mestrado de ensino de História no $3^{\circ}$ ciclo e no ensino secundário, e da área de Metodologia do ensino da História, pretendeu-se compreender como é que as ideias desses alunos, futuros professores de História, desenvolviam-se ao longo do seu processo formativo. Trata-se de um estudo exploratório, qualitativo-descritivo, de foco longitudinal, contando com participantes selecionados por conveniência e em linha com a Grounded Theory. Assim, criou-se uma tarefa para os alunos, futuros professores de História, quer de $1^{\circ}$ ano quer de $2^{\circ}$ ano do referido mestrado, que foi aplicada em dois momentos distintos: na primeira aula, numa lógica de levantamento de ideias prévias e carências/necessidades desses futuros professores de História; e na última aula, com a intenção de mapear o desenvolvimento, ou não, das ideias iniciais numa lógica de metacognição. Essa tarefa trata-se de um questionário de resposta aberta que foi respondido individualmente por escrito pelos futuros professores em dois momentos, como já referido. A tarefa/questionário proposta foi:

No inicio deste percurso é importante refletir acerca de algumas dimensões no âmbito do seu crescimento profissional.

1. Descreva-me a sua ideia de 
a. como deve ser uma aula de História.

b. uma "coisa" que espera que os seus alunos aprendam com as suas aulas de História.

2. 0 que é que fazemos quando pensamos historicamente?

3. Qual o seu propósito como professor de História? (GAG0, 2018, p. 511).

\section{IDEIAS DE FUTUROS PROFESSORES DE HISTÓRIA - UMA ANÁLISE}

Propõe-se uma análise global das ideias dos alunos por meio de nuvens de ideias que surgiram no primeiro e no segundo momento de resposta, ou seja, no início e no fim do processo formativo. A grandeza da palavra nas nuvens de ideias é proporcional à frequência do seu aparecimento nas respostas dadas pelos futuros professores de História.

Denotou-se que num primeiro momento os futuros professores colocavam ao mesmo nível o seu foco no conhecimento e nos alunos quando pensam na aula de História. Já no segundo momento o seu foco principal é a palavra aluno, seguido de palavras como professor, ideias, construir e fontes, conforme demonstram as Figuras 1 e 2.

Questão la - Descreva-me a sua ideia de como deve ser uma aula de História.

Figura 1 - Aula de História, momento 1

Figura 2 - Aula de História, momento 2

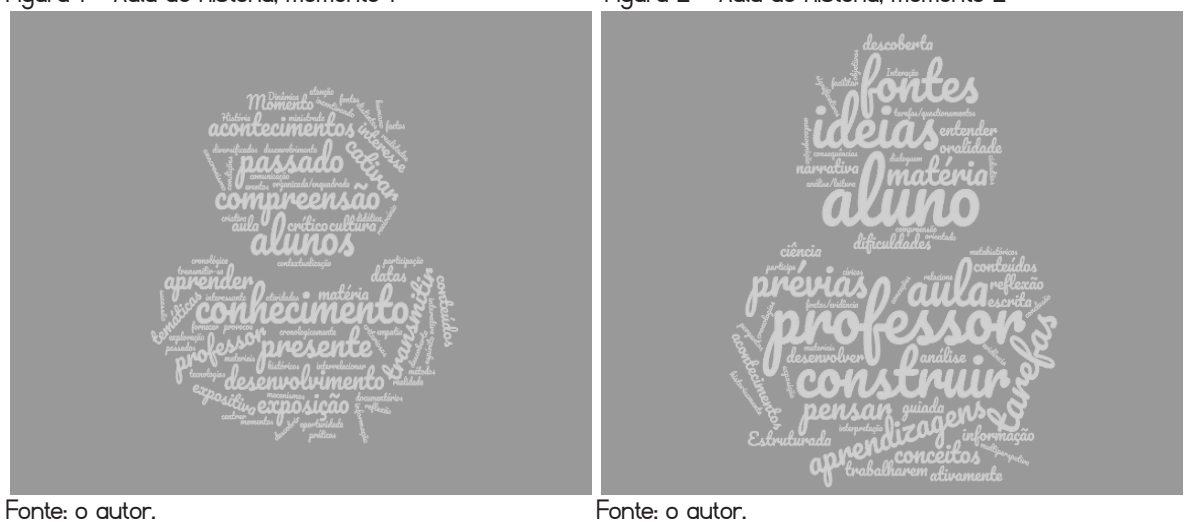

Relativamente ao que esperam que os seus alunos aprendam nas suas aulas de História, os futuros professores de História, no primeiro momento, centram-se na História e no passado, já num segundo momento o seu foco é colocado no pensamento, na compreensão e nas fontes, conforme as figuras seguintes. 
Questão $1 \mathrm{~b}$ - Descreva-me a sua ideia de uma "coisa" que espera que os seus alunos aprendam com as suas aulas de História.

Figura 3 - Aprender História, momento 1 Figura 4 - Aprender História, momento 2

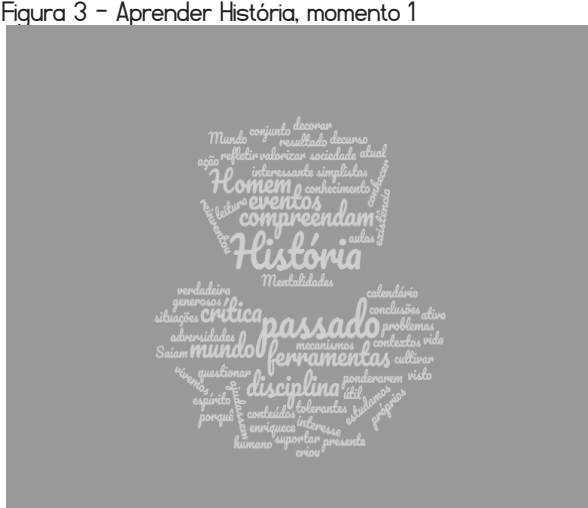

Fonte: o autor.

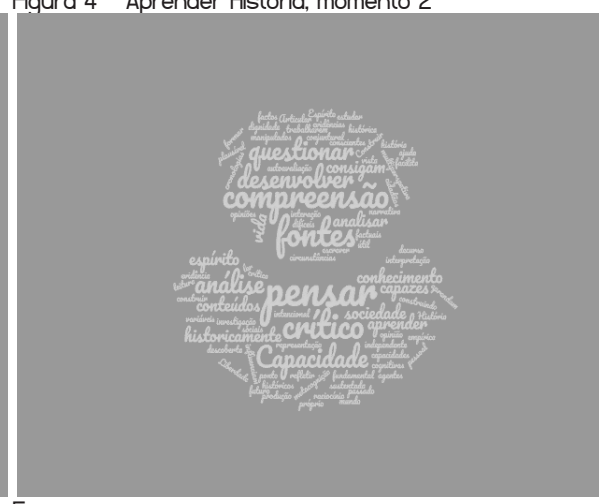
Fonte: o autor.

Quando questionados acerca do que fazemos quando pensamos historicamente, os futuros professores de História revelaram ideias distintas no primeiro e no segundo momentos. Assim, os futuros professores, num primeiro momento, centram-se no conhecimento, já no segundo momento o seu foco é colocado no pensamento e na compreensão histórica.

Questão 2 - 0 que fazemos quando pensamos historicamente?
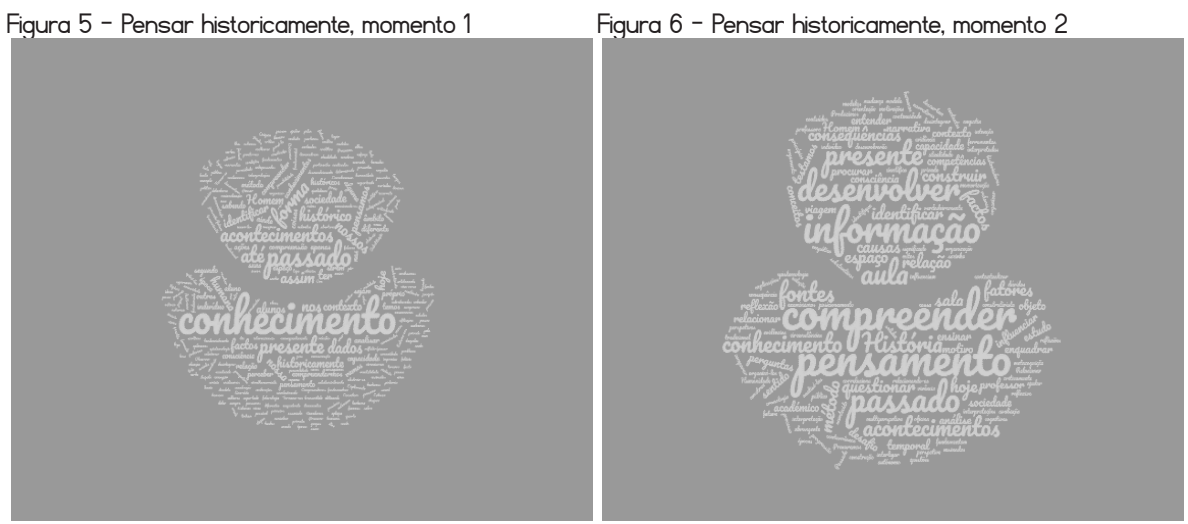

Fonte: o autor. Fonte: o autor.

Os futuros professores de História foram, também, convidados a pensar acerca do seu propósito como professor de História, nos dois momentos distintos. Em ambos os 
momentos a palavra central do propósito desses futuros professores de História são os alunos, mas no primeiro momento surge em seguida o conhecimento, enquanto no segundo momento surgem aprendizagem, crítica, pensamento e desenvolvimento.

Questão 3 - Qual o seu propósito como professor de História?

Figura 7 - Propósito de professor, momento 1

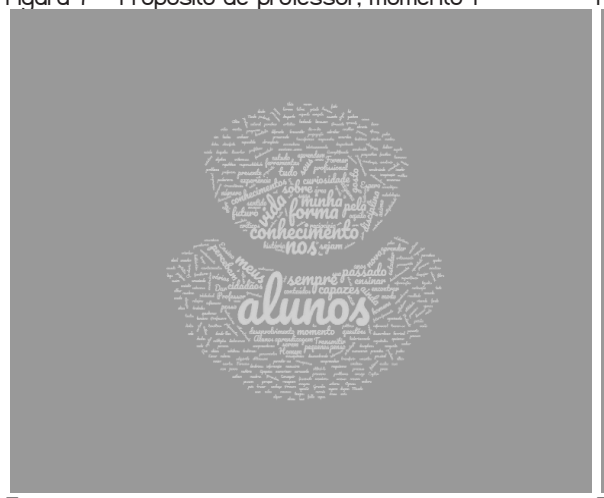

Fonte: o autor.
Figura 8 - Propósito de professor, momento 2

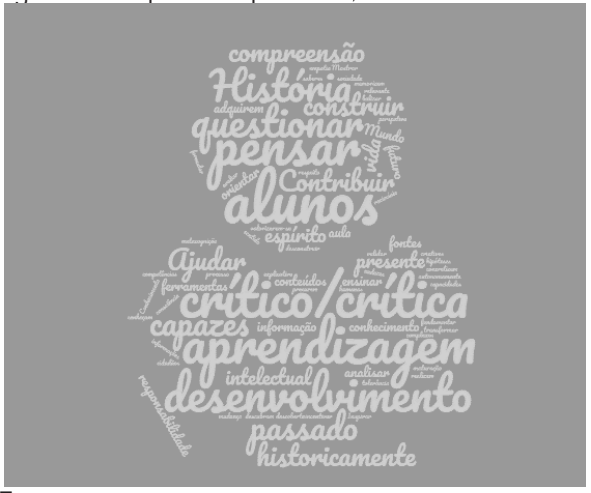

Fonte: o autor.

Atendendo às ideias presentes nas figuras anteriores, parece ser possível afirmar que os futuros professores de História, num primeiro momento, encontravam-se muito centrados no conhecimento substantivo da História em linha com uma visão mais tradicional do processo de ensino-aprendizagem com o qual conviveram de forma mais regular ao longo da sua formação, mas demonstravam preocupação com os alunos, que também estavam no centro da sua atenção. Num segundo momento emergem ideias mais em linha com as preocupações e os princípios defendidos pela linha de investigação em Educação Histórica, surgindo já a preocupação do desenvolvimento do pensamento, da compreensão histórica, da construção e desenvolvimento dos alunos por meio de fontes, da crítica e do questionamento.

Para além dessa análise/categorização mais aberta das ideias dos futuros professores de História, partilha-se aqui a análise/categorização seletiva e axial das ideias que emergiram das respostas dos participantes às questões 2 e 3; relembrando: "2. 0 que fazemos quando pensamos historicamente?"; "3. Qual o seu propósito como professor de História?".

As ideias mais frequentes, no primeiro momento, que surgiram das respostas dos futuros professores de História relativamente à questão "2. 0 que é que fazemos quando pensamos historicamente?", parecem estar em linha com três grandes núcleos, que se apresentam por ordem de frequência. Assim, 
a. pensamos historicamente quando nos colocamos no Lugar do Outro, isto é, a História contribuiu para nos inserirmos num contexto social, econômico ou político, para nos colocarmos no lugar dos nossos antepassados, de forma a percebermos as suas formas de ação, colocando-nos na pele do Outro;

b. pensamos historicamente numa lógica de Origem e Continuum, isto é, a História permite-nos conhecer a nossa origem, as nossas raízes, o que nos permite retirar algumas ilações para conseguirmos perceber ou resolver uma questão/problema do presente;

c. pensamos historicamente quando compreendemos que o ser humano é uma construção continuada, isto é, a História desenvolve as capacidades de observar, compreender e identificar os passos dos seres humanos nas mais variadas perspetivas, do espaço mais privado ao público, bem como desenvolver a análise de dados por meio da crítica e de abertura para aceitarmos novos dados mesmo que possam desintegrar a realidade que dávamos como conhecida. A História permite tornarmo-nos mais humanos, mais conscientes, atendendo aos contextos e aos "porquês" da realidade passada e presente, bem como contribui para tecermos horizontes de expectativa passiveis de enquadrar o nosso caminho futuro mediante as nossas decisões e ações.

No que se refere às ideias que emergiram das respostas à questão "3. Qual o seu propósito como professor de História?", surgiram, também, três grandes núcleos de ideias, que se apresentam por ordem de frequência. Assim, os futuros professores de História têm como propósito da sua ação profissional:

a. motivar e gerir, ou seja, têm como foco captar a atenção e o interesse dos alunos de modo a transmitirem o conhecimento histórico de forma motivadora para que os seus alunos não pensem que a "História é uma seca [é aborrecida], que não tem interesse" (informação verbal);

b. formar cidadãos, ou seja, consideram que o conhecimento da História dá aos alunos as ferramentas necessárias para que as novas gerações sejam compostas por cidadãos críticos e criativos;

c. contribuir para que os alunos compreendam que o ser humano tem "fibra" para mudar o mundo sempre que necessário, colocando-se nos ombros de seres humanos com vivências anteriores para desenharem um melhor futuro. 
Pretendem desenvolver o espírito crítico dos alunos, pois essa competência será fulcral para a sua vida, e que os alunos compreendam que a História é um processo de reflexão repleto de questionamento.

No segundo momento de realização da tarefa, assistiram-se a alterações relativamente aos núcleos de ideias apresentadas pelos alunos e sua frequência. Assim, no caso da questão "2. 0 que é que fazemos quando pensamos historicamente?", o núcleo de ideias de origem e continuum não teve expressão, tendo-se desenvolvido as ideias de nos colocarmos no Lugar do Outro e no sublinhar da multiperspectiva como natural e legítima em História; seguindo-se, a emergência de ideias da construção do pensamento histórico em linha com um novo humanismo na procura da dignidade humana. Relativamente às ideias que surgiram nas respostas à questão "3. Qual o seu propósito como professor de História?", no segundo momento, continuaram a persistir com maior frequência as ideias que a História forma cidadãos, embora se sublinhe a necessidade de compreender a História per si e não ao serviço da cidadania. As preocupações de gerir e motivar os alunos foram atenuadas, não se revelando como um dos propósitos dos futuros professores de História, que estão, agora, mais preocupados em fomentar o pensamento e a compreensão histórica de formas cada vez mais sofisticadas por meio do desenvolvimento de tarefas desafiadoras historicamente.

A análise das ideias das restantes respostas está, neste momento, a decorrer, pretendendo-se, também, cruzar todas as ideias apresentadas com os portfólios reflexivos que os futuros professores de História produziram como um dos instrumentos de avaliação da área de Metodologia do ensino da História.

\section{ALGUMAS CONSIDERAÇÕES}

Ao longo do último ano letivo propôs-se que a caminhada de formação para se vir a ser professor de História fosse alicerçada nos princípios partilhados pela investigação em educação histórica e nas pistas que os vários e diversos estudos ao nível de ideias de alunos e professores nos têm facultado. Relembramos que é fundamental ouvir a "voz do professor e voz do aluno" (SCHMDT, 2016, p. 30), e, nesse sentido, desenharam-se algumas tarefas e desafios.

0 questionário de resposta aberta, que constitui a primeira tarefa da primeira aula dos futuros professores, tinha como principal objetivo conhecer o mundo prévio de vivências, experiências e sentidos que estes tinham construído ao longo da sua longa experiência como alunos, bem como acerca das suas carências e necessidades. Compreendeu-se que a maioria 
dos futuros professores de História, por meio do seu período de observação, continuavam centrados na transmissão de conhecimento substantivo da História, mas que esta fosse motivadora atendendo aos seus alunos. Por outro lado, esses futuros professores de História consideravam, na sua grande maioria, que para pensarmos historicamente teríamos de nos colocarmo na perspetiva do Outro, e alguns referiam que tal situação deveria se feita com o mesmo respeito que gostaríamos que tivessem conosco.

Com base nessas ideias foram construídos vários desafios e tarefas ao longo das experiências de aprendizagem definidas para a área de Metodologia do ensino de História. Para compreender se as ideias desses futuros professores tinham, ou não, se alterado, e se sim, como, na última aula convidaram-se os participantes a responder, novamente, à primeira tarefa.

Face aos dados recolhidos e à sua análise parece poder-se afirmar que as ideias dos futuros professores se alteraram. Se no início do processo tinham como foco o conhecimento, a transmissão deste, a motivação e a formação de cidadãos, no segundo momento as suas ideias sugerem como preocupação o desenvolvimento do pensamento, da compreensão histórica, do uso de fontes, da crítica e da aprendizagem atendendo ao questionamento contínuo, em linha com o respeito e a dignidade dos seres humanos de qualquer realidade, seja ela próxima seja estrangeira/estranha.

Todo esse processo formativo e investigativo fez emergir algumas considerações relativas à formação de professores de História. Parece ser crucial formar professores que:

a. compreendam a História como uma forma de ver, ler e fazer sentido do mundo - passado, presente ou horizontes de expectativa. Compreendam a aprendizagem histórica como uma reorientação cognitiva, que permite ver o mundo de forma(s) mais complexa(s);

b. desenhem e desenvolvam as suas aulas de forma que os alunos desenvolvam o seu pensamento histórico e compreendam a História per si, como um processo que contribui para as suas tomadas de decisão, para as suas ações e para a orientação de si próprio no tempo;

c. concebam que a História tem valor per si, pois contribui para o desenvolvimento do pensamento independente e o respeito pelo ser humano, em linha com uma sociedade que se pauta pela democracia. Sublinha-se, no entanto, que a História não está ao serviço de uma cidadania definida;

d. desenvolvam a sua identidade profissional em linha com um profissionalismo democrático, concretizando uma escola aberta ao fluir de ideias, à promoção da informação para todos, ao desenho de várias possibilidades de resolução 
de problemas usando a análise e a reflexão crítica da(s) evidência(s), problema(s), política(s). Uma escola na qual a democracia não seja um "ideal" a ser perseguido, mas um guia para a vida. A escola e a aula têm de ser palco do respeito pela dignidade humana, pelo direitos individuais e de todos os seres humanos, sem exceção.

Num mundo cada vez mais global, em que demandas externas parecem querer definir central e externamente o que significa a educação e ser professor, urge que a formação de professores de História, inicial ou continuada, paute-se pelos princípios da sua própria disciplina que se alicerça no pensamento crítico, cruzado e multiperspectivado com o propósito de compreender o mundo de forma(s) mais complexa(s), centrando-se mais no que nos une do que no que nos separa - um novo Humanismo.

\section{REFERÊNCIAS}

BARCA, I. Aula-oficina: do projeto à avaliação. In: BARCA, I. (org.) Para uma educação de qualidade: actas das quartas jornadas de educação histórica. Braga: CIED/IEP, 2004. p. 131-144.

DAY, C.; SACHS, J. Professionalism, performativity and empowerment: discourses in the politics, policies and purposes of continuing professional development. In: DAY, C.; SACHS, J. (ed.). International handbook on the continuing professional development of teachers. Maidenhead: Open University Press, 2004. p. 3-32.

DAY, C. Desenvolvimento profissional de professores: os desafios da aprendizagem permanente. Porto: Porto Editora, 2001.

DONOVAN, M. S.; BRANSFORD, J. D. How students learn history, mathematics and science in the classroom. Washington: National Research Council, 2005.

ESTRELA, M. T.; ESTRELA, A. A formação contínua de professores numa encruzilhada. In: BIZARRO, R.; BRAGA, F. (org.). Formação de professores de línguas estrangeiras: reflexões, estudos e experiências. Porto: Porto Editora, 2006. p. 7379.

FLORES, M. A. Algumas reflexões em torno da formação inicial de professores. Revista Educação, v. 33, n. 3, p. १८२-188, set./dez. 2010.

FLORES, M. A. Tendências e tensões no trabalho docente: reflexões a partir da voz dos professores. Perspectiva, v. 29, n. 1, p. 161-191, jan./jun. 2011.

GAG0, M. Ser professor de história em tempos dificeis: início de um processo formativo. Antíteses, v. 11, n. 22, p. 505-515, jul./dez. 2018. 
GERMINARI, G. Educação histórica: a constituição de um campo de pesquisa. Revista HISTEDBR On-line, n. 42, p. 54-70, jun. 2011.

KORTHAGEN, F. A. J. Situated learning theory and the pedagogy of teacher education: towards an integrative view of teacher behavior and teacher learning. Teaching and Teacher Education, v. 26, p. 98-106, 2010.

KORTHAGEN, F. A. J. et al. Linking practice and theory: the pedagogy of realistic teacher education. Mahwah: Lawrence, 2001.

LEE, P. Historical literacy and transformative history. In: PERIKLEOUS, L.; SHEMILT, D. (ed.). The future of the past: why history education matters. Chipre: UNDP-ACT, 2011. p. 129-168.

LORTIE, D. School-teacher: a sociological study. Chicago: University of Chicago Press, 1975.

RÜSEN, J. Studies in metahistory. Pretoria: Human Sciences Research Council, 1993.

SACHS, J. Teacher education and the development of professional identity: learning to be a teacher. In: DENICOLO, P.; KOMPF, M. (ed.). Connecting policy and practice: challenges for teaching and learning in schools and universities. 0xford: Routledge, 2005. p. 5-21.

SACHS, J. Teacher professional identity: competing discourses, competing outcomes. Journal of Education Policy, v. 16, n. 2, p. 149-161, 2001.

SCHMIDT, M.A. Interculturalidade, humanismo e educação. histórica: formação da consciência histórica é mais do que literacia histórica? In: SCHMIDT, M. A.; FRONZA, M. (org.). Consciência histórica e interculturalidade: investigações em educação histórica. Curitiba: W\&A Editores, 2016. p. 21-33.

URBAN, A. C. A didática da história nos manuais destinados à formação de professores. Diálogos, v. 19, n. 1, p. 275-287, jan./abr. 2015.

Endereço para correspondência: Rua da Universidade, 4710-057, Braga, Portugal; mgago@ie.uminho.pt

Roteiro, Joaçaba, U. 45, p. 1-18, jan./dez. 2020 | e21736 |E-ISSN 2177-6059 
